infections also deserves special mention, especially for the excellence of the illustrations.

It is strange to find a chapter on rheumatism and connective tissue diseases amongst the more orthodox haematological subjects, but this is the penalty of having sections in such a volume. In fact the haemoglobinopathies could, for example, well be called chemical pathology, the fungal infections could be included in the bacteriological section, and it appears that even this book may well encourage those who regard the four main branches of pathology as four quite divorced disciplines. Yet this is obviously not the intention of the General Editor.

The General Editor points out that this new series does not mean at all that the earlier editions are now out of date and superseded by this edition. On the contrary, entirely new subjects have deliberately been chosen for inclusion. It becomes therefore even more imperative that there should not be a delay of anything like nine years before the fourth series appears. In fact the hospital pathologist will be demanding a regular flow of such excellent surveys to enable him to carry out the functions so well described by the General Editor in his preface.

A. GORDON SIGNY

THE BRITISH MEDICAL BULlETIN, Vol. 16, No. 3. 'Insulin'. London: British Council. 1960.

The current number of the British Medical Bulletin, dealing with insulin, is no exception to the extremely high standard of the various special numbers.

After introductory historical surveys by Young and by Best, an excellent review by Sanger of his brilliant work on the chemistry and structure of insulin is followed by an account of oxytocin, vasopressin, corticotrophin and melanotrophin, polypeptide pituitary hormones, the structures of which have been elucidated by methods applied by Sanger. Methods of insulin assay are described by Stewart: the extension of these to the investigation of plasma insulin and its antibodies and other antagonists has been critically discussed by Randle and Taylor, by Valance-Owen, and by P. H. Wright. If anything, in this work there is perhaps an overemphasis on and preoccupation with methods employing the rat diaphragm.

The critical reviews of the action of insulin on carbohydrate metabolism and on fatty acid metabolism by Fisher and by Folley and Greenbaum respectively are the most stimulating of all the contributions. Fisher discusses critically the hexokinase hypothesis of the action of insulin and the possible role of insulin in increasing the permeability of cells to sugar, a possibility later considered by Randle and Young. Fisher tritely remarks that 'if it is true that the major action of insulin in relation to carbohydrate metabolism is to regulate access of glucose to peripheral cells, then in the biochemical sense it may have no action at all on carbohydrate metabolism'.

Folley and Greenbaum make it clear that there are two defects in insulin deficiency, first in the conversion of extracellular glucose to intracellular glucose-6phosphate and a second defect at the level of conversion of acetyl coenzyme $A$ to the 4-carbon stage of the synthesis of fatty acids. Considering work on the liver, mammary gland, and adipose tissue, they discuss the possibility that the primary action of insulin might be to facilitate glucose oxidation and so provide TPNH via the pentose phosphate pathway and thus secondarily stimulate fatty acid synthesis in contrast to primarily stimulating the synthesis of fatty acids and by oxidizing TPNH to TPN provide a stimulus to carbohydrate metabolism.

Korner and Manchester have discussed the relationship of insulin to protein metabolism and describe the work in this field leading up to their own observations that insulin in vivo can affect the ability of microsomes to assemble activated amino-acids into polypeptide chains. On the other hand, Randle and Young consider that insulin is most likely to play an intracellular role separate from its effect on the entry of substances into the cell, but confess that it is not known at present whether or not the many effects of insulin are likely to be explicable in terms of a single action.

The four clinically biased papers are excellent and include an account of the relationship of endocrine disorders and insulin action by Russell Fraser, and a highly critical account of the clinical applications of insulin by Oakley who confesses that the long-acting insulins have not fulfilled all that had originally been hoped; he admits to the impossibility of reproducing blood sugar control comparable with that of normal subjects even with frequent doses of insulin. The relation between the molecular structure and hypoglycaemig activity has been considered by Mahler. Indeed, the development of the oral hypoglycaemic agents has beef⿱ highly empirical and it is still impossible to determine the chemical or physical feature responsible for their activity. Nabarro provides a valuable account of the clinical effectiveness of the various insulin substitutes but states that it is too early 'to attempt any long-term assessment of the place of any sulphonamide derivatives in the treatment of diabetes mellitus'.

It is becoming a commonplace that acquisition of knowledge passes first through a phase when all seems straightforward and easily understood, only to be followed by a phase of great complexity. Our knowledge of the functions and mechanism of the action of insulin is no exception. When insulin was first isolated 40 years ago, all seemed simple and it would then have been difficult to foresee that even now we would still be ignorant of so much of this subject. This special number of the British Medical Bulletin provides a synthesis of present-day knowledge which will be invaluable for all concerned with this hormone, whether research workers or clinicians essentially preoccupied with its therapeutic use.

CHARLES H. GRAY

DISEASE AND THE ADVANCEMENT OF BASIC SCIENCE. Edited by Henry K. Beecher. (Pp. xi +416 ; illustrated. 100s.) Harvard University Press (London: Oxford University Press). 1960.

This book, based on the Lowell lectures of 1958, is concerned with the stimulus given by medical studies to investigations in the basic sciences. The first chapter is by Linus Pauling and the last by René Dubos and the long list of contributors is a distinguished one. The range of 
topics is wide indeed, with Cori writing on carbohydrate metabolism, Enders on viruses, Castle on physiological advances stimulated by studies on anaemia, Bauer on rheumatic diseases, Aub on cancer and normal cell growth, and many others. The theme of the series of lectures is brilliantly illustrated and it is good to be reminded that medicine is not always the beneficiary in the relationship between itself and the basic sciences. The moral which emerges, however, is that the relation is essentially one of mutual dependence and, as Paul Weiss says, "The meaning of setting the two apart, as if they were opposites or even separable, escapes me. Clinical investigation and biological research are integral parts of the same endeavour'. In the last chapter, Dubos, in a sombre contribution, points out that medical Utopias, no less than political Utopias, are likely to prove illusory and he warns that unless medical scientists are prepared to take the long view they 'may come to know the anguish that atomic scientists experienced as they watched the tragic effects of their scientific triumphs'. This is a book for every pathologist with a live interest in the relation between his work and the whole body of science. Most of it is easy to read, all of it is stimulating, and many of the contributions have the merit of posing more questions than they answer.

F. HAMPSON

BIOCHEMICAL VALUES IN CLINICAL MEDICINE: THE RESULTS FOLLOWING PATHOLOGICAL OR PHYSIOLOGICAL CHANGE. Robert Duncan Eastham. (Pp. iv + 144. 15s.) Bristol: John Wright. 1960.

The average medical registrar will find this book attractive because it gives him, in summarized form, the means of interpreting chemical pathological results. But it is impossible in a book of this size to indicate the criteria of utility of any investigation; a critical approach to laboratory results is essential if the patient is to have proper care and therefore this book is unlikely to help the patient. There are one or two factual errors, e.g., the alkaline phosphatase tends to rise with advancing years, not to fall. A number of investigations have been included, such as the determination of $\beta$-glucuronidase in urine and the serum diphenylamine reaction, which are not in common use and would be better omitted. The limitations of other investigations might have been brought out more clearly: for example, the congo red test is not usually helpful, Bence-Jones protein is commonly absent from the urine in myelomatosis, and the hippuric acid synthesis test yields unsatisfactory results in the presence of a peptic ulcer. There are always statements with which one must disagree, and amongst these must be included the statement that the upper limit of the serum cholesterol level in adults is $250 \mathrm{mg}$./ $100 \mathrm{ml}$. (it is higher than this and increases with age), and the failure to make clear the significant relationship between the average daily protein intake and the blood urea clearance. The statement that estimation of radioactive iodine uptake by the thyroid gland is more accurate than estimation of the B.M.R. may be true if iodine has not been exhibited recently, but the investigation is one to be avoided in the youthful; qualifications such as these must not be omitted.

\section{The Association of Clinical Pathologists}

SUMMARIES of two papers presented at the meeting of the Association of Medical Pathologists and the Association of Clinical Biologists on 29 October, 1960 at the Royal College of Surgeons, London, follow. They were omitted from the full account of the meeting published in the November issue of the Journal.

\section{MINIMAL CRITERIA FOR THE DIAGNOSIS OF MEGALOBLASTIC ANAEMIA OF PREGNANCY}

I. RANNIE and H. MCTAGGART said that during a 21-month period 45 cases of megaloblastic anaemia of pregnancy were diagnosed in a series of 3,741 women delivered in hospital.

Specimens of venous blood were collected with Sequestrin as anticoagulant and in most cases were not received in the laboratory until the following day, having been stored overnight at room temperature or $4^{\circ} \mathrm{C}$. and then transported by van.

When the specimen was received the haemoglobin was estimated. If this was $75 \%(11 \cdot 1 \mathrm{~g} . \%)$ or below, or if the case was already being followed, the reticulocytes and packed cell volume were estimated and a buffy coat film was made.

The packed cell volume was estimated using a Hawksley micro-haematocrit centrifuge, after which the capillary tube containing the blood was cut and the buffy coat and some of the underlying red cells were used to make a smear which was stained with Leishman's stain.

The diagnosis of megaloblastic anaemia was not made until megaloblasts appeared in the peripheral blood but the diagnosis can in fact be established before this time by finding macrocytes, polylobing of polymorphonuclear leucocytes and normoblasts in which the degree of haemoglobinization is in advance of nuclear maturation.

Details of four of the cases were given, with special reference to time of diagnosis, the buffy coat film, and the appearance of megaloblasts in the blood following intravenous or intramuscular iron therapy.

Accurate haemoglobin estimations are an important part of antenatal care. Any haemoglobin found to be below $75 \%(11 \cdot 1 \mathrm{~g} . \%)$ should be followed by the examination of buffy coat films so that folic acid deficiency anaemia of pregnancy can be diagnosed and treated as early as possible.

\section{METABOLIC CHANGES FOLLOWING SEVERE TRAUMA}

I. G. GRABER said that mortality from severe skeletal trauma has been reduced from $40 \%$ to $1.4 \%$ in the last decade largely due to adequate blood transfusion, but 